\title{
Purines and the Anti-Epileptic Actions of Ketogenic Diets
}

\author{
Susan A. Masino*, ${ }^{*}$, Masahito Kawamura, Jr. ${ }^{1,2}$, David N. Ruskin ${ }^{1}$, Jeremy Gawryluk ${ }^{3}$, \\ Xuesong $\mathrm{Chen}^{3}$ and Jonathan D. Geiger ${ }^{3}$
}

\author{
${ }^{I}$ Department of Psychology/Neuroscience Program, Trinity College, Hartford, Connecticut, 06106, USA, ${ }^{2}$ Department \\ of Pharmacology, Jikei University School of Medicine, Minato-ku, Tokyo, Japan, and ${ }^{3}$ Department of Pharmacology, \\ Physiology and Therapeutics, University of North Dakota School of Medicine and Health Sciences, Grand Forks, North \\ Dakota 58201, USA
}

\begin{abstract}
Ketogenic diets are high in fat and low in carbohydrates and represent a well-established and effective treatment alternative to anti-epileptic drugs. Ketogenic diets are used for the management of a variety of difficult-to-treat or intractable seizure disorders, especially pediatric refractory epilepsy. However, it has been shown that this dietary therapy can reduce seizures in people of all ages, and ketogenic diets are being applied to other prevalent medical conditions such as diabetes. Although used effectively to treat epilepsy for nearly 90 years, the mechanism(s) by which ketogenic diets work to reduce seizures remain ill-understood. One mechanism receiving increased attention is based on findings that ketogenic diets increase the brain energy molecule ATP, and may also increase the levels and actions of the related endogenous inhibitory neuromodulator adenosine. ATP and adenosine have both been identified as important modulators of seizures; seizures increase the actions of these purines, these purines regulate epileptic activity in brain, adenosine receptor antagonists are pro-convulsant, and adenosinergic mechanisms have been implicated previously in the actions of approved anti-epileptic therapeutics. Here we will review recent literature and describe findings that shed light on mechanistic relationships between ketogenic diets and the purines ATP and adenosine. These emerging mechanisms hold great promise for the effective therapeutic management of epileptic seizures and other neurological conditions.
\end{abstract}

Keywords: Adenosine, ATP, brain, epilepsy, metabolism, seizures.

\section{INTRODUCTION}

Epilepsy is a prevalent brain disorder characterized by a predisposition to generate seizures due to excessive or asynchronous neuronal activity in brain [1]. The incidence of epilepsy is particularly high in young children $(\leq 5$ years old), in young adults especially those engaged in combat, and in those over the age of $65[2,3]$. As a neurological disorder, epilepsy is poorly classified as it has multiple known and unknown genetic and environmental causes, manifestations, seizure types, and identifiable syndromes; an onset of epilepsy associated with head trauma, central nervous system infections, and tumors may occur at any age [3]. The incidence and prevalence of epilepsy have been increasing because of combat-associated head injuries and an aging population, and this trend is predicted to continue $[4,5]$. Thus, new therapeutic strategies are needed, and effective interventions could benefit a broad and growing population.

Antiepileptic drugs (AEDs) are used typically and widely for the treatment of epilepsy. The aim of AED treatment is to control seizures while minimizing adverse side-effects; unfortunately AEDs are effective for only 60-70\% of epileptic individuals, and undesirable side-effects are not uncommon [6-8]. In ancient times, epilepsy was treated through the dietary intervention of starvation, which forces a switch from

*Address correspondence to this author at the Neuroscience Program / Psychology Department, Trinity College, Life Sciences Center 210, 300 Summit St., Hartford, CT 06106, USA; Tel: (860) 297-2557; Fax: (860) 297-2538; E-mail: susan.masino@trincoll.edu glucose-based to ketone-based metabolism. This simple but extreme treatment led to the hypothesis and its clinical confirmation that maintaining ketone-based metabolism by limiting carbohydrates, while still ingesting adequate calories, could control seizures [9]. Currently a major alternative and non-pharmacological treatment for epilepsy is adhering to a high-fat, low-carbohydrate ketogenic diet (KD), and over many years its efficacy has been confirmed in retrospective, prospective, and multi-center studies [10-13]. Since its inception, KD has been employed to maintain ketosis and control epileptic seizures primarily in children who do not respond well to AEDs [14, 15].

\section{KETOGENIC DIETS AND EPILEPSY: APPLICA- TIONS, BENEFITS AND LIMITATIONS}

The KD requires strict compliance to maintain anticonvulsant effects. It limits the consumption of carbohydrates persistently and sufficiently such that the carbohydrate content does not provide enough glucose to serve as an available energy source. Without adequate glucose, the brain is forced metabolically to switch from mostly glycolytic pathways to ketolytic mechanisms whereby ketones are produced (mainly in the liver) and used as the main fuel to generate ATP for cellular metabolism.

The KD ratio prescribed clinically is a specific ratio of fat to protein plus carbohydrate. A typical KD contains the ratio of 4:1 (fat: protein + carbohydrates). Approximately $90 \%$ of dietary calories are derived from fat whereas $<5 \%$ comes from carbohydrates [16, 17]. Proteins are added to the diet to meet requirements depending on the individual's age 
and size. In some treatment protocols, fluids and calories are restricted - total caloric intake is targeted to $75 \%$ of the recommendation for the individual's age; however there is no evidence that forced caloric restriction or fluid restriction is necessary for the clinical benefit to be observed [18].

As noted, an analogous switch to ketone-based sources of cellular energy occurs during fasting/starvation. Without imposing unhealthy fasting/starvation approaches, adherence to a KD can provide adequate calories and energy while protecting against generation of epileptic seizures. The diet reduces seizure frequency by greater than $90 \%$ for one-third of children on the diet and by greater than $50 \%$ for an additional one-third of children $[19,20]$. It appears that a KD is more or less as effective in controlling seizure activity in adults as it is in treating children with epilepsy, but there have been comparatively few studies on adults [21, 22]. One reason why a KD is more commonly applied in and perceived as successful in pediatric epilepsy is that it is easier to initiate, control food intake and maintain this strict diet in children. Most pediatric patients that respond well to the KD are weaned from the diet after two years because the anticonvulsant effect achieved is often permanent [23, 24].

Although the KD is highly effective, it does have its shortcomings; main criticisms include it being a diet that is restrictive and unpalatable. In addition, it can cause constipation, kidney stones, and, depending on the saturated fat composition of the diet, cardiovascular complications [25-28]. A low-carbohydrate diet with a healthier fat composition might reduce complications [29]. More research is clearly needed in this area to determine more accurately side effects and long terms consequences.

To date, the key mechanisms underlying the success of a $\mathrm{KD}$ in reducing seizures are unclear [30, 31]. Proposed mechanisms include increased GABA, increased mitochondrial gene expression, direct effects of ketones on neurons, $\mathrm{pH}$ changes, and altered ion channels - particularly $\mathrm{K}^{+}$channels. This knowledge gap has limited the use of KDs for epilepsy and potentially other disorders, as well as stymied efforts to develop drugs that could take advantage of the anticonvulsant mechanisms mobilized by a KD [32]. Despite its efficacy, KD treatment has inherent drawbacks and limitations and a better mechanistic understanding of its actions could lead to better diet-based approaches including those with fewer restrictions and complications. Importantly, an understanding of underlying mechanisms should result in new directions for basic and clinical research [33].

Here we focus on the relationship between adhering to a $\mathrm{KD}$ and increased brain levels of ATP and adenosine as a new insight into epilepsy treatment. The purines ATP and adenosine link metabolism to neuronal activity [34], and cell bioenergetics may be a key regulator of seizure activity [35, 36]. Importantly, adenosine is an endogenous anticonvulsant [37-39] which is effective in numerous seizure models, including acute and chronic electroconvulsive and pharmacological paradigms [40-44], and is also effective in pharmacoresistant kainate-induced seizures [45-47].

Adenosine acting at the adenosine $A_{1}$ receptor $\left(A_{1} R\right)$ subtype could be the final key mechanism by which adhering to a KD prevents seizures [48, 49]. Although more research is needed, to date there are a few seizure models where both adenosine and a KD have been shown to be effective, including electrical kindling of the amygdala in rats [42-44, 50], acute bicuculline injection [41, 51, 52], pentylenetetrazol kindling in mice [53-55], and the epileptogenic phase after kainate treatment $[45-47,56,57]$. Overall, a purine-targeting metabolic strategy - ultimately increasing the actions of the anticonvulsant molecule adenosine - has great potential to treat a wide variety of epileptic seizures.

\section{EPILEPSY AND ENERGY METABOLISM}

During seizures neurons undergo prolonged depolarization that leads to large fluxes of ions across plasma membranes. As a result there is intracellular accumulation of sodium and calcium ions, and an increased requirement to expend large amounts of energy (mostly ATP) to re-establish the interior milieu. ATP is necessary to maintain resting membrane potentials, and depletion of intracellular ATP in an effort to export accumulated ions can lead to bioenergetic crisis and/or redox catastrophe. Sodium-potassium-ATPase is largely responsible for maintaining these ionic gradients [58]; under basal conditions it has been estimated that ATPase consumes $25-40 \%$ of the brain's energy [59], and after seizure activity ATPase likely consumes an even greater percentage of brain energy to restore the resting membrane potential. Decreased levels of ATP can reduce the cell's energy charge and its ability to maintain homeostasis and normal neuronal function and signaling, and, during an acute energy demand such as a seizure, the need for ATP can very readily and rapidly supersede supply. Thus, adequate intracellular ATP is central to controlling cellular energy, seizure generation, and neuronal membrane polarity.

Compared to the large and constant levels of ATP inside the cell, extracellular ATP is relatively insignificant and transient. A net dephosphorylation of ATP to ADP, AMP and adenosine occurs extremely rapidly (the $t_{1 / 2}$ of ATP in the extracellular space is about $200 \mathrm{~ms}$ [60]). Together, ATP and its core molecule adenosine are intricately involved in maintaining cellular energy levels and in controlling neuronal excitability via cell-surface receptors. Intracellular adenosine is especially important because it is a very sensitive measure of the balance between cellular energy supplies and energy demand. Its actions to reduce neuronal activity and energy demand and re-establish equity between supply and demand via feedback on cell-surface receptors is a concept central to adenosine being considered a retaliatory metabolite [61]. Extracellular adenosine is a powerful endogenous anticonvulsant, with great potential for treating all types of epileptic seizures. Traditionally, adenosine has been recognized as the brain's own anticonvulsant molecule and a powerful endogenous neuromodulator: tonic levels are present throughout the extracellular space, it is released from cells during seizures, ischemia, and hypoxia [62-64], its actions can also be increased by stimuli such as changes in temperature and $\mathrm{pH}$ [65-70], and it may be more sensitive to these changes during conditions of increased excitability [71].

Adenosine is released during seizures, and adenosine through its activation of high-affinity $\mathrm{A}_{1} \mathrm{Rs}$ contributes to termination of seizures by reducing neuronal excitability $[45$, 72-74]. Activation of $\mathrm{A}_{1} \mathrm{Rs}$ pre- and postsynaptically decreases excitatory neurotransmitter release [75] and hyperpolarizes postsynaptic membrane potentials by promoting po- 
tassium conductance [76]. The brain in general and the seizure-prone hippocampus in particular contain high levels of $\mathrm{A}_{1} \mathrm{Rs}$. There is abundant evidence that the powerful anticonvulsant role of endogenous adenosine occurs through this receptor subtype [77-80]. For example the ictal EEG events of bicuculline-injected rats were suppressed by focal application of adenosine [78] and $A_{1} R$ agonists suppress even pharmacoresistant epilepsy of kainate injected mice [45]. Conversely, antagonists of $\mathrm{A}_{1} \mathrm{Rs}$ are pro-convulsant [81]. Thus, adenosine is similar to the KD in that both are effective at reducing seizures that are refractory to other treatments. Unfortunately, drug-based strategies that directly target adenosine $\mathrm{A}_{1} \mathrm{Rs}$ generally face vexing pharmacological obstacles including peripheral side effects such as reduced heart rate and blood pressure [82]. More recently, localized adenosine based-therapies show significant promise but are necessarily invasive and best suited to well-localized, focal seizures $[80,83]$.

Extracellular ATP is a major source of extracellular adenosine $[84,85]$, and, as noted, is metabolized rapidly to adenosine [60]; these enzymatic reactions are catalyzed by a variety of ecto-ATPases and 5'-nucleotidases [60]. Thus, increased levels of either purine in seizure-prone brain areas containing $\mathrm{A}_{1} \mathrm{Rs}$ could help to either prevent or to terminate seizures. At this time it is neither well-understood how a KD differentially affects purinergic mechanisms and metabolism in various cell types in the central nervous system, nor has it been determined what roles different cell types might play in a KD's anticonvulsant benefits. Nevertheless, it has been established that ATP and adenosine in the central nervous system can originate from neurons themselves as well as from other cell types, most notably from astrocytes. Astrocytes are abundant, and particularly complex in humans [86, 87], and purines released from astrocytes influence synaptic transmission. Astrocytes release ATP through hemichannels as well as from neurosecretory vesicles; extracellular adenosine derived from astrocytic ATP influences neuronal excitability, plasticity, and sleep [88-90]. However, astrocyte involvement in the relationship between purines and epilepsy is complicated by findings that astrogliosis occurs in epilepsy and brain injury, astrocytes transport adenosine into the cell interior, adenosine kinase very actively catalyzes the phosphorylation of adenosine to AMP within astrocytes, and increased levels of adenosine kinase decreases the extracellular levels and actions (including anticonvulsant actions) of adenosine [91].

\section{PURINES AND THE KETOGENIC DIET}

Many hypotheses have been advanced and tested in ongoing attempts to determine mechanisms responsible for the antiepileptic effects of a KD. Acidosis, dehydration and ketosis were the first mechanisms to be considered when the KD was first introduced as a metabolic strategy which could mimic fasting-induced seizure protection [15]. None of these initial mechanisms appeared sufficient to explain clinical observations, and subsequently, investigators attributed the protective actions of a KD to alterations in levels of neurotransmitters (including GABA, norepinephrine and glutamate), glucose restriction, activation of ATP-sensitive $\mathrm{K}^{+}$ channels, circulating factors including polyunsaturated fatty acids and their downstream effectors, decreased neuronal excitability, transformations of cerebral energy metabolism and increased purines [15, 30, 48]. Identifying critical anticonvulsant mechanisms underlying the success of KD therapy remains a topic of intense research, and changes in gene expression, altered energy metabolism, and changes in the levels and actions of purines are very strong candidates $[48$, 49, 92-94].

For over 30 years it has been recognized that KD can lead to increased levels of ATP in brain [92] and it also increases the ratio of phosphocreatine to ATP [95]. More recently we used methods able to provide precise and accurate measures of brain energy metabolites in brain and reported that rats fed a calorie-restricted KD for three weeks had increased ratios of phosphocreatine to creatine in hippocampus [94]; such increases suggest that alternative sources of high energy phosphate are available and might thereby protect against ATP utilization and depletion. Subsequently, we showed that KD increased levels of ATP in brains of KD-fed animals. 1

Some clinical reports suggest that a KD can offer seizure protection promptly $[96,97]$, and some research shows that acute ketone treatment can be directly anticonvulsant [98]. At least two reports show that ketones or an in vitro analogue of ketogenic metabolism increases hyperpolarization via postsynaptic ATP-sensitive $\mathrm{K}^{+}$channels $[99,100]$. However, many reports note that a KD can take several days or weeks before becoming maximally effective [eg. 101]. Accordingly, it was hypothesized that this delay was due to alterations in gene expression generally and more specifically due to alterations in genes involved in the control of energy metabolism [94]. Using gene microarray technology, normal 37-41 day old rats placed on a KD for 21 days were found to have upregulated genes for oxidative phosphorylation. In agreement with this, mitochondrial biogenesis was increased, and, as noted above, brain levels of phosphocreatine relative to creatine were increased [94]. Thus, improved brain bioenergetic status might play an important role in the anti-seizure effects of KD.

Measured increases in cell bioenergetics in conjunction with the gene array data suggest strongly that brain energy metabolism in general and purines in particular might be mechanisms central to the therapeutic effects of the KD. Increasingly, recent research and proposed hypotheses about the KD suggest that higher levels of both ATP and adenosine underlie some of the anticonvulsant success as well as emerging applications for a $\mathrm{KD}$ and analogous ketogenic metabolic strategies [33, 48, 49, 100]. Augmenting extracellular adenosine offers both pre- and postsynaptic inhibitory mechanisms as well as established clinical potential beyond epilepsy including brain injury, pain and sleep disorders [33, 88]. Furthermore, understanding the mechanisms underlying the success of KD for epilepsy would be a major breakthrough, as this metabolism-based therapy can alleviate seizures even in cases of intractable epilepsy.

Clinical observations that a KD can be effective in intractable epilepsy suggest that although the spectrum of mechanisms underlying the success of KD therapy could overlap, they must be distinct from those targeted primarily by AEDs.

\footnotetext{
${ }^{1}$ Masino SA, Gockel JA, Wasser CD, Pomeroy LT, Wagener JF, Gawryluk JW, Geiger JD. The relationship among ATP, adenosine and a ketogenic diet. Soc Neurosci Abstr. 2007: 595.12.
} 
Research in animal models is very clear that adenosine is a powerful global and local seizure-suppressor, and an adenosine or $A_{1} R$ deficiency alone is sufficient to trigger seizure activity [47, 102]. To date, a variety of adenosinergic mechanisms have been implicated in the actions of AEDs including AEDs interacting with $\mathrm{A}_{1} \mathrm{Rs}$ and increasing their anti-epileptic effectiveness, and AEDs binding to $\mathrm{A}_{1} \mathrm{Rs}$ directly [103-105]. When considering all of the intra- and extracellular regulatory mechanisms for controlling the levels and actions of purines in brain, and the respective contributions of neurons and astrocytes, the greatest net benefit of the anticonvulsant effects of purines would be achieved by 1) maintaining overall cell energy levels, 2) at least maintaining (if not increasing) cellular levels of ATP, and 3) increasing levels of extracellular adenosine, either directly or as a consequence of increased extracellular ATP and its dephosphorylation to adenosine.

In addition to evidence that a $\mathrm{KD}$ in vivo may change ATP and adenosine, increases in these purines have been implicated in cellular consequences of ketogenic metabolism both in vitro and in vivo. For example, moderate hypoglycemia or glycolytic inhibition can both increase adenosine [106-108] and offer anticonvulsant benefits [109, 110]. Recent electrophysiological evidence shows that sufficient or high intracellular ATP and lowered extracellular glucose mobilizes an autocrine inhibition via $\mathrm{A}_{1} \mathrm{Rs}$ [100]. Diverse findings that a KD or ketogenic metabolic strategies work through purines, and particularly through adenosine, does not negate or eliminate other metabolic changes precipitated by this metabolic switch. Rather, these findings may help simultaneously pinpoint specific and critical mechanisms and identify a new strategy for adenosine regulation, opening new avenues for the treatment of seizure disorders and a broad array of other diseases.

\section{SUMMARY}

Traditionally, the KD is used mainly in children. While it has limitations, KD therapy may be more effective in the management of childhood seizures than currently available AEDs [111], and can offer permanent benefits [112]. The KD might also slow the progression of this disorder and thus be antiepileptogenic [56, 113]. Certainly more research is needed in this area. Unfortunately, until the mechanism(s) by which the KD provides protection are better delineated, this knowledge gap makes is difficult to fashion an even better and more widely accessible therapeutic approach. Nevertheless, with respect to the relationship among KDs and purines, a better insight into how this metabolic switch influences purines could yield new approaches to purine-based therapies which have shown potential for treating a diverse array of acute and chronic conditions.

\section{ACKNOWLEDGEMENTS}

The authors acknowledge grant funding from the National Institutes of Health, CHDI and the National Science Foundation.

\section{REFERENCES}

[1] Fisher RS, van Emde BW, Blume W, et al. Epileptic seizures and epilepsy: definitions proposed by the International League Against Epilepsy (ILAE) and the International Bureau for Epilepsy (IBE). Epilepsia 2005; 46: 470-2.
[2] Hauser WA, Annegers JF. Risk factors for epilepsy. Epilepsy Res Suppl 1991; 4: 45-52.

[3] Duncan JS, Sander JW, Sisodiya SM, Walker MC. Adult epilepsy. Lancet 2006; 367: 1087-100.

[4] Frey LC. Epidemiology of posttraumatic epilepsy: a critical review. Epilepsia 2003; 44: 11-7.

[5] Jetter GM, Cavazos JE. Epilepsy in the elderly. Semin Neurol 2008; 28: 336-41.

[6] Vajda FJE. Pharmacotherapy of epilepsy: new armamentarium, new issues. J Clin Neurosci 2007; 14: 813-23.

[7] Camfield PR, Camfield CS. Antiepileptic drug therapy: when is epilepsy truly intractable? Epilepsia 1996; 37(Suppl 1): S60-5.

[8] Louis EK. Minimizing AED adverse effects: improving quality of life in the interictal state in epilepsy care. Curr Neuropharmacol 2009; 7: 106-14.

[9] Wilder RM. The effects of ketonemia on the course of epilepsy. Mayo Clin Proc 1921; 2: 307-8.

[10] Henderson CB, Filloux FM, Alder SC, Lyon JL, Caplin DA. Efficacy of the ketogenic diet as a treatment option for epilepsy: metaanalysis. J Child Neurol 2006; 21: 193-8.

[11] Wiznitzer M. From observations to trials: the ketogenic diet and epilepsy. Lancet Neurol 2008; 7: 471-2.

[12] Neal EG, Chaffe H, Schwartz RH, et al. The ketogenic diet for the treatment of childhood epilepsy: a randomised controlled trial. Lancet Neurol 2008; $7:$ 500-6.

[13] Kossoff EH, Rho JM. Ketogenic diets: evidence for short- and long-term efficacy. Neurotherapeutics 2009; 6: 406-14.

[14] Freeman JM, Vining EPG, Pillas DJ, Pyzik PL, Casey JC, Kelly LM. The efficacy of the ketogenic diet-1998: a prospective evaluation of intervention in 150 children. Pediatrics 1998; 102: 1358-63.

[15] Schwartzkroin PA. Mechanisms underlying the anti-epileptic efficacy of the ketogenic diet. Epilepsy Res 1999; 37: 171-80.

[16] Huttenlocher PR. Ketonemia and seizures: metabolic and anticonvulsant effects of two ketogenic diets in childhood epilepsy. Pediatr Res 1976; 10: 536-40.

[17] Edelstein SF, Chisholm M. Management of intractable childhood seizures using the non-MCT oil ketogenic diet in 20 patients. J Am Diet Assoc 1996; 96: 1181-2.

[18] Sinha SR, Kossoff EH. The ketogenic diet. Neurologist 2005; 11: 161-70.

[19] Thiele EA. Assessing the efficacy of antiepileptic treatments: the ketogenic diet. Epilepsia 2003; 44(Supp1 7): 26-9.

[20] Sharma S, Gulati S, Kalra V, Agarwala A, Kabra M. Seizure control and biochemical profile on the ketogenic diet in young children with refractory epilepsy - Indian experience. Seizure 2009; 18: 4469.

[21] Baborka CJ. Epilepsy in adults: results of treatment by ketogenic diet in one hundred cases. Arch Neurol 1930; 6: 904-14.

[22] Sirven J, Whedon B, Caplan D, et al. The ketogenic diet for intractable epilepsy in adults: preliminary results. Epilepsia 1999; 40: 1721-6.

[23] Martinez CC, Pyzik PL, Kossof EH. Discontinuing the ketogenic diet in seizure-free children: recurrence and risk factors. Epilepsia 2007; 48: 187-90.

[24] Caraballo RH, Cersósimo RO, Sakr D, Cresta A, Escobal N, Fejerman N. Ketogenic diet in patients with myoclonic-astatic epilepsy. Epileptic Disord 2006; 8: 151-5.

[25] Best TH, Franz DN, Gilbert DL, Nelson DP, Epstein MR. Cardiac complications in pediatric patients on the ketogenic diet. Neurology 2000; 54: 2328-30.

[26] Bank IM, Shemie SD, Rosenblatt B, Bernard C, Mackie AS. Sudden cardiac death in association with the ketogenic diet. Pediatr Neurol 2008; 39: 429-31.

[27] Hartman AL, Vining EP. Clinical aspects of the ketogenic diet Epilepsia 2007; 48: 31-42.

[28] Sampath A, Kossoff EH, Furth SL, Pyzik PL, Vining EP. Kidney stones and the ketogenic diet: risk factors and prevention. J Child Neurol 2007; 22: 375-8.

[29] Jenkins DJA, Wong JMW, Kendall CWC, et al. The effect of a plant-based low-carbohydrate ("Eco-Atkins") diet on body weight and blood lipid concentrations in hyperlipidemic subjects. Arch Int Med 2009; 169: 1046-54.

[30] Bough KJ, Rho JM. Anticonvulsant mechanisms of the ketogenic diet. Epilepsia 2007; 48: 43-58.

[31] Nylen K, Likhodii S, Burnham WM. The ketogenic diet: proposed mechanisms of actions. Neurotherapeutics 2009; 6: 402-5. 
[32] Rho JM, Sankar R. The ketogenic diet in a pill: is this possible? Epilepsia 2008; 49(Suppl 8): 127-33.

[33] Masino SA, Kawamura M, Jr, Wasser CD, Pomeroy LT, Ruskin DN. Adenosine, ketogenic diet and epilepsy: the emerging therapeutic relationship between metabolism and brain activity. Curr Neuropharmacol 2009; 7: 257-68.

[34] Kato F, Kawamura M, Shigetomi E, Tanaka J-I, Inoue K. ATP- and adenosine-mediated signaling in the central nervous system: synaptic purinoceptors: the stage for ATP to play its "dual-role". J Pharmacol Sci 2004; 94: 107-11.

[35] Latini S, Pedata F. Adenosine in the central nervous system: release mechanisms and extracellular concentrations. J Neurochem 2001; 79: 463-84.

[36] Dragunow M. Purinergic mechanisms in epilepsy. Prog Neurobiol 1988; 31: 85-108.

[37] Whitcomb K, Lupica CR, Rosen JB, Berman RF. Adenosine involvement in postictal events in amygdala-kindled rats. Epilepsy Res 1990; 6: 171-9.

[38] Boison D. Adenosine kinase, epilepsy and stroke: mechanisms and therapies. Trends Pharmacol Sci 2006; 27: 652-8.

[39] Dunwiddie TV. Endogenously released adenosine regulates excitability in the in vitro hippocampus. Epilepsia 1980; 21: 541-8.

[40] de Sarro G, de Sarro A, Meldrum BS. Anticonvulsant action of 2chloroadenosine injected focally into the inferior colliculus and substantia nigra. Eur J Pharmacol 1991; 194: 145-52.

[41] Concas A, Santoro G, Mascia MP, et al. Anticonvulsant doses of 2chloro- $\mathrm{N}^{6}$-cyclo-pentyladenosine, an adenosine $\mathrm{A}_{1}$ receptor agonist, reduce GABAergic transmission in different areas of the mouse brain. J Pharmacol Exp Ther 1993; 267: 844-51.

[42] Dragunow M, Goddard GV. Adenosine modulation of amygdala kindling. Exp Neurol 1984; 84: 654-65.

[43] Pourgholami MH, Rostampour M, Mirnajafi-Zadeh J, Palizvan MR. Intra-amygdala infusion of 2-chloroadenosine suppresses amygdala-kindled seizures. Brain Res 1997; 775: 37-42.

[44] Abdul-Ghani A-S, Attwell PJE, Bradford HF. The protective effect of 2-chloroadenosine against the development of amygdala kindling and on amygdala-kindled seizures. Eur J Pharmacol 1997; 326: 7-14.

[45] Gouder N, Fritschy J-M, Boison D. Seizure suppression by adenosine $A_{1}$ receptor activation in a mouse model of pharmacoresistant epilepsy. Epilepsia 2003; 44: 877-85.

[46] Li T, Ren G, Kaplan DL, Boison D. Human mesenchymal stem cell grafts engineered to release adenosine reduce chronic seizures in a mouse model of CA3-selective epileptogenesis. Epilepsy Res 2009; 84: 238-41.

[47] Li T, Ren G, Lusardi T, et al. Adenosine kinase is a target for the prediction and prevention of epileptogenesis in mice. J Clin Invest 2008; 118: 571-82.

[48] Masino SA, Geiger JD. Are purines mediators of the anticonvulsant/neuroprotective effects of ketogenic diets? Trends Neurosci 2008; 31: 273-8

[49] Masino SA, Geiger JD. The ketogenic diet and epilepsy: Is adenosine the missing link? Epilepsia 2009; 50: 332-3.

[50] Hori A, Tandon P, Holmes GL, Stafstrom CE. Ketogenic diet: effects on expression of kindled seizures and behavior in adult rats. Epilepsia 1997; 38: 750-8.

[51] Uhlemann ER, Neims AH. Anticonvulsant properties of the ketogenic diet in mice. J Pharmacol Exp Ther 1972; 180: 231-8.

[52] Bough KJ, Gudi K, Han FT, Rathod AH, Eagles DA. An anticonvulsant profile of the ketogenic diet in the rat. Epilepsy Res 2002; 50: 313-25.

[53] Akula KK, Dhir A, Kulkarni SK. Systemic administration of adenosine ameliorates pentylenetetrazol-induced chemical kindling and secondary behavioural and biochemical changes in mice. Fundam Clin Pharmacol 2007; 21: 583-94.

[54] Otani K, Yamatodani A, Wada H, Mimaki T, Yabuuchi H. Effect of ketogenic diet on convulsive threshold and brain monoamine levels in young mice. No To Hattatsu 1984; 16: 196-204.

[55] Hansen SL, Nielsen AH, Knudsen KE, et al. Ketogenic diet is antiepileptogenic in pentylenetetrazole kindled mice and decrease levels of $N$-acylethanolamines in hippocampus. Neurochem Int 2009; 54: 199-204.

[56] Su SW, Cilio MR, Sogawa Y, Silveira D, Holmes GL, Stafstrom CE. Timing of ketogenic diet initiation in an experimental epilepsy model. Dev Brain Res 2000; 125: 131-8.
[57] Muller-Schwarze AB, Tandon P, Liu Z, Lang Y, Holmes GL, Stafstrom CE. Ketogenic diet reduces spontaneous seizures and mossy fiber sprouting in the kainic acid model. Neuroreport 1999; 10: $1517-22$.

[58] Wallace DC. A mitochondrial paradigm of metabolic and degenerative diseases, aging, and cancer: a dawn for evolutionary medicine. Annu Rev Gen 2005; 39: 359-407.

[59] Albers RW, Siegel GJ, Basic Neurochemistry: Molecular, cellular and medical aspects. 6th ed. Philadelphia, PA: Lippincott Williams \& Wilkins 1999

[60] Dunwiddie TV, Diao LH, Proctor WR. Adenine nucleotides undergo rapid, quantitative conversion to adenosine in the extracellular space in rat hippocampus. J Neurosci 1997; 17: 7673-82.

[61] Newby AC, Worku Y, Holmquist CA. Adenosine formation: evidence for a direct biochemical link with energy metabolism. Adv Myocardiol 1985; 6: 273-84.

[62] Berman RF, Fredholm BB, Aden U, O'Connor WT. Evidence for increased dorsal hippocampal adenosine release and metabolism during pharmacologically induced seizures in rats. Brain Res 2000; 872: 44-53.

[63] Fredholm BB, Dunwiddie TV, Bergman B, Lindström K. Levels of adenosine and adenine nucleotides in slices of rat hippocampus. Brain Res 1984; 295: 127-36.

[64] Olsson T, Cronberg T, Rytter A, et al. Deletion of the adenosine A1 receptor gene does not alter neuronal damage following ischaemia in vivo or in vitro. Eur J Neurosci 2004; 20: 1197-204.

[65] Gabriel A, Klussmann FW, Igelmund P. Rapid temperature changes induce adenosine-mediated depression of synaptic transmission in hippocampal slices from rats (non-hibernators) but not in slices from golden hamsters (hibernators). Neuroscience 1998; 86: 67-77.

[66] Gourine AV, Llaudet E, Dale N, Spyer KM. Release of ATP in the ventral medulla during hypoxia in rats: role in hypoxic ventilatory response. J Neurosci 2005; 25: 1211-8.

[67] Otsuguro K-i, Yamaji Y, Ban M, Ohta T, Ito S. Involvement of adenosine in depression of synaptic transmission during hypercapnia in isolated spinal cord of neonatal rats. J Physiol 2006; 574: 835-47.

[68] Masino SA, Dunwiddie TV. Temperature-dependent modulation of excitatory transmission in hippocampal slices is mediated by extracellular adenosine. J Neurosci 1999; 19: 1932-9.

[69] Masino SA, Latini S, Bordoni F, Pedata F, Dunwiddie TV. Changes in hippocampal adenosine efflux, ATP levels, and synaptic transmission induced by increased temperature. Synapse 2001; 41: 58-64.

[70] Dulla CG, Dobelis P, Pearson T, Frenguelli BG, Staley KJ, Masino SA. Adenosine and ATP link $\mathrm{P}_{\mathrm{CO} 2}$ to cortical excitability via $\mathrm{pH}$ Neuron 2005; 48: 1011-23.

[71] Dulla CG, Frenguelli BG, Staley KJ, Masino SA. Intracellular acidification causes adenosine release during states of hyperexcitability in the hippocampus. J Neurophysiol 2009; 102: 1984-93.

[72] Dunwiddie TV, Hoffer BJ, Fredholm BB. Alkylxanthines elevate hippocampal excitability. Evidence for a role of endogenous adenosine. Naunyn Schmiedebergs Arch Pharmacol 1981; 316: 326-30.

[73] During MJ, Spencer DD. Adenosine: a potential mediator of seizure arrest and postictal refractoriness. Ann Neurol 1992; 32: 61824.

[74] Ribeiro JA, Sebastião AM, de Mendonca A. Adenosine receptors in the nervous system: pathophysiological implications. Prog Neurobiol 2003; 68: 377-92.

[75] Thompson SM, Haas HL, Gähwiler BH. Comparison of the actions of adenosine at pre- and postsynaptic receptors in the rat hippocampus in vitro. J Physiol 1992; 451: 347-63.

[76] Greene RW, Haas HL. The electrophysiology of adenosine in the mammalian central nervous system. Prog Neurobiol 1991; 36: 32941.

[77] Etherington LA, Frenguelli BG. Endogenous adenosine modulates epileptiform activity in rat hippocampus in a receptor subtypedependent manner. Eur J Neurosci 2004; 19: 2539-50.

[78] Anschel DJ, Ortega EL, Kraus AC, Fisher RS. Focally injected adenosine prevents seizures in the rat. Exp Neurol 2004; 190: 544 7.

[79] Boison D. Adenosine and epilepsy: from therapeutic rationale to new therapeutic strategies. Neuroscientist 2005.; 11: 25-36. 
[80] Huber A, Padrun V, Déglon N, Aebischer P, Möhler H, Boison D. Grafts of adenosine-releasing cells suppress seizures in kindling epilepsy. Proc Natl Acad Sci USA 2001; 98: 7611-6.

[81] Morgan PF, Deckert J, Jacobson KA, Marangos PJ, Daly JW. Potent convulsant actions of the adenosine receptor antagonist, xanthine amine congener (XAC). Life Sci 1989; 45: 719-28.

[82] Elzein E, Zablocki J. A1 adenosine receptor agonists and their potential therapeutic applications. Expert Opin Investig Drugs 2008; 17: 1901-10.

[83] Boison D. Adenosine augmentation therapies (AATs) for epilepsy: prospect of cell and gene therapies. Epilepsy Res 2009; 85: 131-41.

[84] Pascual O, Casper KB, Kubera C, et al. Astrocytic purinergic signaling coordinates synaptic networks. Science 2005; 310: 113-6.

[85] Bekar L, Libionka W, Tian GF, et al. Adenosine is crucial for deep brain stimulation-mediated attenuation of tremor. Nat Med 2008; 14: 75-80.

[86] Tsacopoulos M, Magistretti PJ. Metabolic coupling between glia and neurons. J Neurosci 1996; 16: 877-85.

[87] Oberheim NA, Takano T, Han X, et al. Uniquely hominid features of adult human astrocytes. J Neurosci 2009; 29: 3276-87.

[88] Fredholm BB, Chen JF, Cunha RA, Svenningsson P, Vaugeois JM. Adenosine and brain function. Int Rev Neurobiol 2005; 63: 191270.

[89] Halassa MM, Florian C, Fellin T, et al. Astrocytic modulation of sleep homeostasis and cognitive consequences of sleep loss. Neuron 2009; 61: 213-9.

[90] Jones BE. Glia, adenosine, and sleep. Neuron 2009; 61: 156-7.

[91] Boison D, Stewart KA. Therapeutic epilepsy research: from pharmacological rationale to focal adenosine augmentation. Biochem Pharmacol 2009; 78: 1428-37.

[92] DeVivo DC, Leckie MP, Ferrendelli JS, McDougal DB, Jr. Chronic ketosis and cerebral metabolism. Ann Neurol 1978; 3: 331-7.

[93] Nakazawa M, Kodama S, Matsuo T. Effects of ketogenic diet on electroconvulsive threshold and brain contents of adenosine nucleotides. Brain Dev 1983; 5: 375-80.

[94] Bough KJ, Wetherington J, Hassel B, et al. Mitochondrial biogenesis in the anticonvulsant mechanism of the ketogenic diet. Ann Neurol 2006; 60: 223-35.

[95] Pan JW, Bebin EM, Chu WJ, Hetherington HP. Ketosis and epilepsy: ${ }^{31} \mathrm{P}$ spectroscopic imaging at $4.1 \mathrm{~T}$. Epilepsia 1999; 40: 7037.

[96] McQuarrie I, Keith HM. Epilepsy in children: relationship of variations in the degree of ketonuria to occurrence of convulsions in epileptic children on ketogenic diets. Am J Dis Child 1927; 34: 101329.

[97] Millichap JG, Jones JD, Rudis BP. Mechanism of anticonvulsant action of ketogenic diet. Am J Dis Child 1964; 107: 593-604.

[98] Rho JM, Anderson GD, Donevan SD, Steve HS. Acetoacetate, acetone, and dibenzylamine (a contaminant in L-(+)- $\beta$ - hydroxybutyrate) exhibit direct anticonvulsant actions in vivo. Epilepsia 2002; 43: 358-61.

[99] Ma W, Berg J, Yellen G. Ketogenic diet metabolites reduce firing in central neurons by opening $\mathrm{K}_{\mathrm{ATP}}$ channels. J Neurosci 2007; 27 : $3618-25$.

[100] Kawamura M, Jr, Ruskin DN, Masino SA. Metabolic autocrine regulation of neurons involves cooperation among pannexin hemichannels, adenosine receptors and $\mathrm{K}_{\text {ATP }}$ channels. J Neurosci 2010; 30: 3886-95.

[101] Appleton DB, deVivo DC. An animal model for the ketogenic diet. Epilepsia 1974; 15: 211-27.

[102] Li T, Lan JQ, Boison D. Uncoupling of astrogliosis from epileptogenesis in adenosine kinase (ADK) transgenic mice. Neuron Glia Biol 2008; 4: 91-9.

[103] Horvat A, Orlić T, Banjac A, Momić T, Petrović S, Demajo M. Inhibition of rat brain ecto-atpase activity by various drugs. Gen Physiol Biophys 2006; 25: 91-105

[104] Łuszczki JJ, Kozicka M, Swiader MJ, Czuczwar SJ. 2-Chloro-N-6cyclopentyladenosine enhances the anticonvulsant action of carbamazepine in the mouse maximal electroshock-induced seizure model. Pharmacol Rep 2005; 57: 787-94.

[105] Skeritt JH, Davies LP, Johnston GA. A purinergic component in the anticonvulsant action of carbamazepine? Eur J Pharmacol 1982; 82: 195-7.

[106] Fowler JC. Purine release and inhibition of synaptic transmission during hypoxia and hypoglycemia in rat hippocampal slices. Neurosci Lett 1993; 157: 83-6.

[107] Zhu PJ, Krnjević K. Adenosine release is a major cause of failure of synaptic transmission during hypoglycaemia in rat hippocampal slices. Neurosci Lett 1993; 155: 128-31.

[108] Zhao YT, Tekkök S, Krnjević K. 2-Deoxy-D-glucose-induced changes in membrane potential, input resistance, and excitatory postsynaptic potentials of CA1 hippocampal neurons. Can J Physiol Pharmacol 1997; 75: 368-74.

[109] Stafstrom CE, Ockuly JC, Murphree L, Valley MT, Roopra A, Sutula TP. Anticonvulsant and antiepileptic actions of 2-deoxy-Dglucose in epilepsy models. Ann Neurol 2009; 65: 435-47.

[110] Marie C, Bralet AM, Gueldry S, Bralet J. Fasting prior to transient cerebral ischemia reduces delayed neuronal necrosis. Metab Brain Dis 1990; 5: 65-75.

[111] Freeman JM, Kossoff EH, Hartman AL. The ketogenic diet: one decade later. Pediatrics 2007; 119: 535-43.

[112] Gasior M, Rogawski MA, Hartman AL. Neuroprotective and disease-modifying effects of the ketogenic diet. Behav Pharmacol 2006; 17: 431-9.

[113] Bough KJ, Schwartzkroin PA, Rho JM. Caloric restriction and ketogenic diet diminish neuronal excitability in rat dentate gyrus in vivo. Epilepsia 2003; 44: 752-60.

(c) Masino et al.; Licensee Bentham Open.

This is an open access article licensed under the terms of the Creative Commons Attribution Non-Commercial License (http://creativecommons.org/licenses/by-nc/3.0/) which permits unrestricted, non-commercial use, distribution and reproduction in any medium, provided the work is properly cited. 